\title{
Concurrent effects of various B additions on grain refinement, Fe intermetallics morphologies, and ductility evolution of Al-7.5Si-0.55 Mg (A357) cast alloy
}

\author{
Ghulam Asghar $^{1}$ - Lingyang Yuan ${ }^{1} \cdot$ Panwen $\mathrm{Han}^{1} \cdot$ Penghuai Fu ${ }^{1} \cdot$ Liming Peng $^{1}$ (I)
}

Received: 16 August 2020 / Accepted: 18 November 2020 / Published online: 26 November 2020

(c) Springer Nature Switzerland AG 2020

\begin{abstract}
Simultaneous effects of boron (B) additions on grain refinement, morphological changes in Fe-intermetallic compounds, and consequent variations in mechanical responses of the cast Al-7.50Si- $0.55 \mathrm{Mg}$ (A357) alloys are evaluated in this research work. The contents $B$ are varied from 0.002 to $0.40 \mathrm{wt}$. \% and subsequent changes in the grain size and Feintermetallics morphologies are assessed through polarized light images, optical micrography, and scanning electron microscopy. A small addition of B $(0.04 \mathrm{wt}$. \%) yields identical refinement result $(620 \mu \mathrm{m})$ as noted for commercial grain refiner Al-5Ti-1B (642 $\mu \mathrm{m})$; whereas, the higher amount (0.40 wt. \% of B) reduces the grain size up to $44 \%(360 \mu \mathrm{m})$. In as-cast state, the structure of the $\pi$-Fe phase is transmuted from plate/needle-type to Chinese-script particles for increased quantities ( $0.10 \sim 0.40 \mathrm{wt}$. \%) of B. Contrarily, the heat-treatment (T6) causes the depletion of $\mathrm{Mg}$ and B from the $\pi$-Fe phase Chinese-script morphologies and disintegrates them by creating segregated regions of Fe particles. These agglomerated areas of Fe particles act as stress concentration points during tensile loading and considerably decrease the ductility values from 6.7 to $1.8 \%$. Therefore, it implies that great care must be taken while developing B containing grain refiners.
\end{abstract}

Keywords Boron addition · Grain refinement · Morphology of Fe-intermetallics · Ductility · A357 cast alloy

\section{Introduction}

The utilization of Al-Si alloys has been diversified comprehensively in aerospace and automobile sectors during the last three decades due to their remarkable castability to fill the intricate cavities, anticorrosion characteristics, light weight, and superior strength to weight ratios [1-4]. Among the broad variety of Al-Si alloys, hypoeutectic A356/357 alloys are typically employed to produce wheels, chassis, manifolds, and cylinder blocks [5]. Optimum mechanical properties (especially a sustainable ductility) are aimed to achieve the desired functionality and performance of these parts/components [6].
Generally, the microstructural features of hypoeutectic alloys are comprised of primary (a-Al) phase, secondary (eutectic) phase, and Fe-rich intermetallic compounds (FeIMCs). The eutectic phase is typically modified by adding $\mathrm{Sr}$ to obtain the spheroidized shape of Si facets at an industrial scale [7-9]. The sole addition of $\mathrm{Bi}$ is reported to be favorable in obtaining the modified eutectic phase [10]; nevertheless, the addition of Bi along with Sr exhibited the poisoning effect and reduced the modification effectiveness to some extent [11]. Moreover, some other studies [12-15] claimed that the inclusion of La significantly modifies the microstructure, mechanical, and corrosion resistance properties of Al-Si alloys. Ahmad R [16] investigated the modification role Ce addition; whereas, Jiang et al.

$\triangle$ Liming Peng, plm616@sjtu.edu.cn | ${ }^{1}$ National Engineering Research Center of Light Alloy Net Forming and State Key Laboratory of Metal Matrix Composite, School of Materials Science and Engineering, Shanghai Jiao Tong University, 200240 Shanghai, P. R. China. 
[17] evaluated the collective effect of rare earth (La and Ce) elements and declared that a suitable amount of rare earth mixture alters almost all microstructure features and improves mechanical properties considerably. Besides, various other studies have shown promising eutectic phase modification results achieved by the addition of the rare earth elements such as Sc [18], Nd [19], and Y [20, 21].

Refined and equiaxed grains of primary phase are essential to enhance strength characteristics as well as to reduce the hot tearing, micro-porosity, and defects vulnerability [22-25]. Titanium (Ti) and Boron (B) containing binary and ternary grain refiners are in use for the industrial production of Aluminum alloys since the 1950s; nonetheless, their crystallographic structure and characteristics revealed and discussed quite in details in 1980s [26]. The contribution of $B$ in the refinement mechanism was critically assessed and explained by Guzowski et al. [27]. Later, McCartney [22] and O'Reilly et al. [28] shed light on the inoculation and nucleation mechanisms of various grain refiners for $\mathrm{Al}$ and its alloys. The most widely employed grain refiner at an industrial scale is an $\mathrm{Al}-5 \mathrm{Ti}-1 \mathrm{~B}$ for $\mathrm{Al}-\mathrm{Si}$ cast components; during solidification, dispersed $\mathrm{TiB}_{2}$ and $\mathrm{TiAl}_{3}$ particles stimulate the nucleation mechanism by yielding equiaxed grains $[25,29,30]$. Moreover, the master alloy (Al-5Ti-1B) produced through electromagnetic stirring and subsequent extrusion method possesses fine and uniformly distributed $\mathrm{TiAl}_{3}$ particles, which significantly improve the grain refinement effect [31]. However, the presence of a higher amount of Si ( 7.5 wt. \%) in A356/357 alloys promotes the formation of a Ti-rich silicide layer on these nuclei sites (regarded as the poisoning effect), which dramatically fades away the refinement effectiveness [32-34]. Kori et al. [35] developed several master alloys containing different ratios of Ti/B and claimed that the master alloy possessing a higher amount of $B$ yields better refinement results. Some other studies proposed that the inclusion of $\mathrm{C}$ in Al-Ti-B master alloys generates the TiBC particles, which expedite the nucleation kinetics during solidification and minimize the poisoning effect [36-38].

Recently, $\mathrm{Nb}$ is identified as a promising grain refiner in terms of thermal and structural parameters [39]; whereas, Nowak et al. [40] recognized that accumulative inclusion of $\mathrm{Nb}$ and $\mathrm{B}$ considerably improved the refinement results. Consequently, several Al-Nb-B based grain refiners particularly Al-2Nb-2B [41] and Al-2.8Nb-0.3B [42] master alloys have been developed for hypoeutectic alloys. It is claimed that niobium aluminides and borides $\left(\mathrm{Al}_{3} \mathrm{Nb}\right.$ and $\mathrm{NbB}_{2}$ particles) are more thermally stable, hence less vulnerable to form silicides resulting in the elimination of poisoning effect [43]. Furthermore, a binary master alloy (Al-3B) was proposed and claimed to be a proficient grain refiner for hypoeutectic alloys, which is less prone to be poisoned by the Si because of the absence of Ti [44-46]. Therefore, it can be inferred that $B$ is an essential element of almost every grain refiner for hypoeutectic alloys and notably contributes in the grain refinement mechanism.

Regardless of some encouraging results and achievements on grain refinement, another inevitable and problematic issue is the existence of $\mathrm{Fe}(0.10 \sim 0.20 \mathrm{wt} . \%)$ as an impurity in commercially produced Al-Si cast alloys [47]. Usually, Fe gets included inadvertently and forms Fe-rich intermetallic compounds (Fe-IMCs), these intermetallics have ruinous effects on mechanical responses (particularly for ductility) because of their brittle nature and promotion of porosity level [48]. The formation of Fe-IMCs mainly depends upon the alloy composition; the most commonly generated Fe-IMCs in A356/357 alloys are plate/ needle-shape $\beta$ - $\mathrm{Al}_{5} \mathrm{FeSi}$ and Chinese-script $\pi-\mathrm{Al}_{8} \mathrm{Si}_{6} \mathrm{Mg}_{3} \mathrm{Fe} /$ $\mathrm{Al}_{9} \mathrm{Si}_{5} \mathrm{Mg}_{3}$ Fe phases [49-51]. The amount of $\mathrm{Mg}$ determines the phase and morphology of Fe-IMCs; low Mg ( $\leq 0.40$ wt. $\%)$ generates $\beta$-phase while a higher Mg amount ( 0.60 wt. \%) usually creates $\pi$-phase Fe-IMCs along with some $\beta$-phase as well $[52,53]$. Minor additions of Be [54], Mn [55], and Sc [56] are reported not only to alter the morphology of the Fe-IMCs but they also minimize the harmful impact of these Fe-IMCs on the mechanical behavior. Moreover, the combinative addition of $\mathrm{Mn}$ and $\mathrm{Cr}$ is found more beneficial than the sole addition of $\mathrm{Mn}$ [57]. Inclusion of Er is claimed to modify the needle/plate-shape $\beta$-phase into small/nodular particles [58]; conversely, Colombo et al. [59] revealed that Er addition increases the porosity fraction and results in the decrement of mechanical properties.

However, seldom a research work has been communicated focusing on the influence of $B$ additions on the morphology of Fe-IMCs and consequently their effects in terms of mechanical properties. Therefore, this study is directed to clarify the synchronized influence of $B$ additions on grain refinement and structural variations of Fe-IMCs. The grain refinement effects of various B (0.002 0.40 wt. \%) additions have been analyzed along with microstructural characterizations of the eutectic Si phase and the morphological transformation of the Fe-IMCs. Moreover, the correlation between microstructure evolution and mechanical properties (especially the ductility) is discussed along with the identification of optimum addition level of $B$ for obtaining good ductility/quality index (Q. I) values.

\section{Materials and methods}

To prepare Al-7.50Si-0.55 Mg (A357) alloys with different $B$ amounts, an electric resistance furnace was deployed to melt the commercial purity $\mathrm{Al}(99.7 \mathrm{wt}$ \%) within a graphite crucible at $720^{\circ} \mathrm{C}$. Master alloy Al-10Ti, Mg, and 
Si (both 99.9 wt. \% of purity) were added upon melting of Al. Master alloy Al-10Sr was added as a modifier for all cast alloys (300 ppm Sr), while an Al-5Ti-1B (0.20 wt. \%) included as a grain refiner (only in $\mathrm{B}-0$ alloy). The addition quantities of $\mathrm{Al}-3 \mathrm{~B}$ were set to achieve the planned amounts of $B$ and it served as a grain refiner as well. After the addition and melting of all alloying elements, the stirring was performed for $2 \sim 3 \mathrm{~min}$ to mix the alloying elements, degassing was done by adding a mixture of halide salts to remove the dissolved hydrogen from the melt, and then slag was skimmed. The melt was allowed to settle down at $724 \pm 5^{\circ} \mathrm{C}$ for $15 \mathrm{~min}$ and eventually casted into the metallic iron mold (preheated at $220^{\circ} \mathrm{C}$ ). The elemental composition analyses were accomplished through inductively coupled-plasma (ICP) method and enlisted in Table 1 along with designated cast alloys codes.

The pieces cut from the bottom side of cast parts by sparing $10 \mathrm{~mm}$ edges were heat treated at $540 \pm 2^{\circ} \mathrm{C}$ for $8 \mathrm{~h}$ and chilled in water at ambient temperature. The schematic diagram and dimensions $(\mathrm{mm})$ of the plate shape tensile sample according to the ASTM-B557 standard testing method for cast Aluminum alloys along with the actual prepared sample are shown in Fig. 1. Tensile specimens of rectangular shape $(15 \times 3.5 \times 2.2 \mathrm{~mm})$ were cut from the solution treated pieces and isothermal aging was conducted at $175 \pm 1^{\circ} \mathrm{C}$ for $6 \mathrm{~h}$. Three samples for each condition (as-cast and heat treated) were tested using Zwick Roell-20 kN material testing equipment using steady stretching speed of $1 \mathrm{~mm} / \mathrm{min}$ to measure the mean and standard deviation values of mechanical properties.

Optical microstructures (OM) were examined through Zeiss Axio Observer A1 while GAIA3 GMU Model 2016 was utilized to accomplish the scanning electron microscopy (SEM), which was provisioned for energy dispersive spectroscopy (EDS) analysis as well. OM and SEM samples were prepared through abrasive grinding method and etched with a $3 \% \mathrm{HF}$ solution; whereas, polarized light (color) images for grain size measurement were captured from the anodized samples in Barker solution (a diluted solution of $5 \mathrm{ml} \mathrm{HBF}_{4}$ and $200 \mathrm{ml}$ water) by passing $30 \mathrm{~V} \mathrm{DC}$ for $110 \mathrm{~s}$. The average values of grain size were computed through Linear-intercept method from 180 independent measurements of equiaxed and/or coarse dendritic (a)
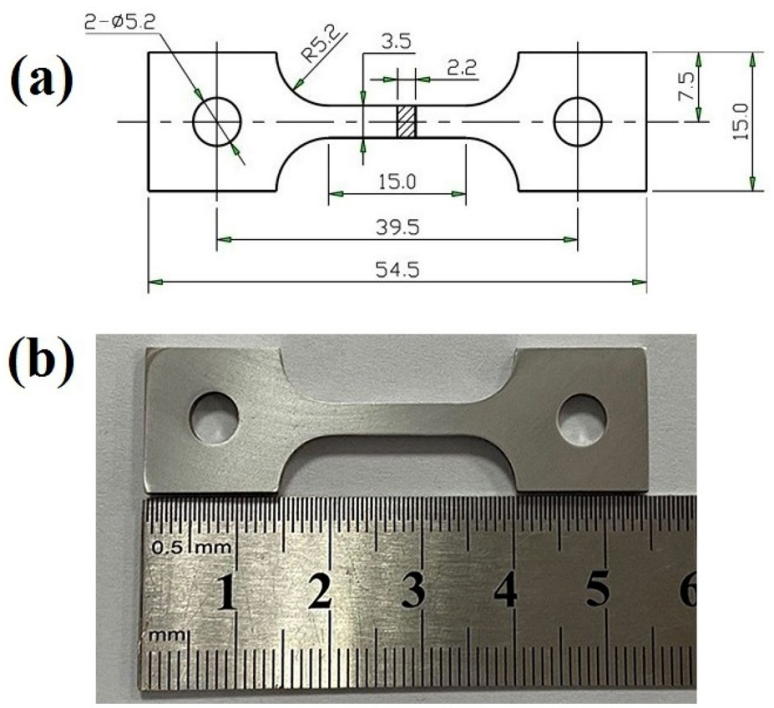

Fig. 1 (a) Schematic diagram and dimensions $(\mathrm{mm})$ of the plate shape tensile sample (b) cut, polished, and prepared tensile sample from the cast section

grains using Image Pro-Plus (IPP) software. Numerical values of the eutectic Si and Fe-IMCs phases are calculated through IPP from OM and SEM ( 10 micrographs of $500 \times$ for each) images, respectively. X-ray Diffraction (XRD) examinations were accomplished through Rigaku Ultima-IV operated at $40 \mathrm{kV}$.

\section{Results}

\subsection{Optical microstructures}

Figure 2 exhibits polarized light images of the cast alloys and variations in their grain structures for different amounts of B. Figure $2 a-b$ micrographs show that almost similar size grains ( 642 and $620 \mu \mathrm{m}$ ) are generated upon minor inclusions of the $\mathrm{Al}-5 \mathrm{Ti}-1 \mathrm{~B}$ and $\mathrm{Al}-3 \mathrm{~B}$ to achieve 0.002 and 0.04 wt. \% quantities of B for B- 0 and B- 1 alloys, respectively. Nevertheless, the grain size is reduced (up to $530 \mu \mathrm{m}$ ) quite considerably by increasing the B amount (0.10 wt. \%) as noticed in Fig. 2c of B-2 alloy. The addition
Table 1 Composition analyses (wt. \%) of Al-7.5Si-0.55 Mg (A357) cast alloys

\begin{tabular}{llllllll}
\hline Alloy Code & $\mathrm{Si}$ & $\mathrm{Mg}$ & $\mathrm{Ti}$ & $\mathrm{Fe}$ & $\mathrm{B}$ & Grain Refiner & Al \\
\hline B-0 & 7.43 & 0.51 & 0.14 & 0.13 & 0.002 & Al-5Ti-1B & Balance \\
B-1 & 7.45 & 0.52 & 0.15 & 0.15 & 0.04 & Al-3B & Balance \\
B-2 & 7.38 & 0.50 & 0.13 & 0.14 & 0.10 & Al-3B & Balance \\
B-3 & 7.32 & 0.52 & 0.15 & 0.13 & 0.20 & Al-3B & Balance \\
B-4 & 7.46 & 0.49 & 0.13 & 0.15 & 0.40 & Al-3B & Balance \\
\hline
\end{tabular}

Al-5Ti-1B master alloy was added (0.20 wt. \%) only in B-0 alloy 

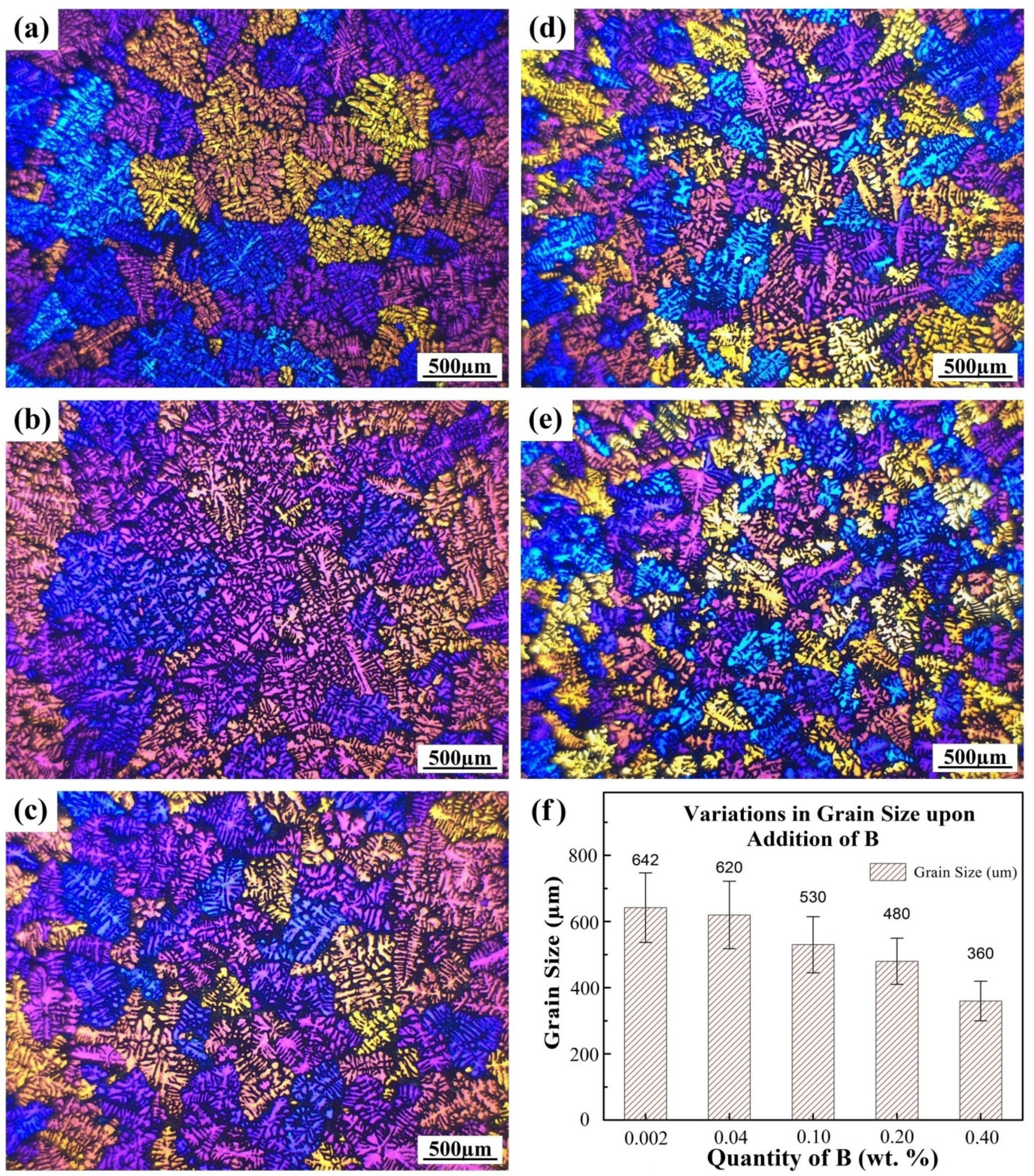

Fig. 2 Polarized light micrographs of A357 cast alloys: (a-e) $0.002,0.04,0.10,0.20$, and 0.40 wt. \% additions of B designated as B-0, B-1, B-2, B-3, and B-4 alloys, respectively; while (f) depicts the variations in average and standard deviation values of measured grain sizes

of higher amounts ( 0.20 and 0.40 wt. \%) of B for B-3 and B-4 alloys further decreased the average values of the grain size to 480 and $360 \mu \mathrm{m}$, respectively as depicted in Fig. 2d-e.
As-cast (AC) and heat treated (T6) microstructures of the cast alloys containing various amounts of $B$ are displayed in Fig. 3a-e and Fig. $3 \mathrm{f}-\mathrm{j}$, respectively without any noticeable casting defects. Some undissolved plate/needle-shape

SN Applied Sciences 
Fig. 3 OM images of $A 357$ cast alloys: $(\mathbf{a}, \mathbf{f}) 0.002,(\mathbf{b}, \mathbf{g})$ 0.04, (c, h) 0.10, (d, i) 0.20, and $(\mathbf{e}, \mathbf{j}) 0.40$ wt. $\%$ of $B$ with assigned names as B-0, B-1, B-2, B-3, and B-4 alloys, correspondingly; whereas, (a-e) as-cast (AC) samples and $(\mathbf{f}-\mathbf{j})$ after heat treatment (T6)
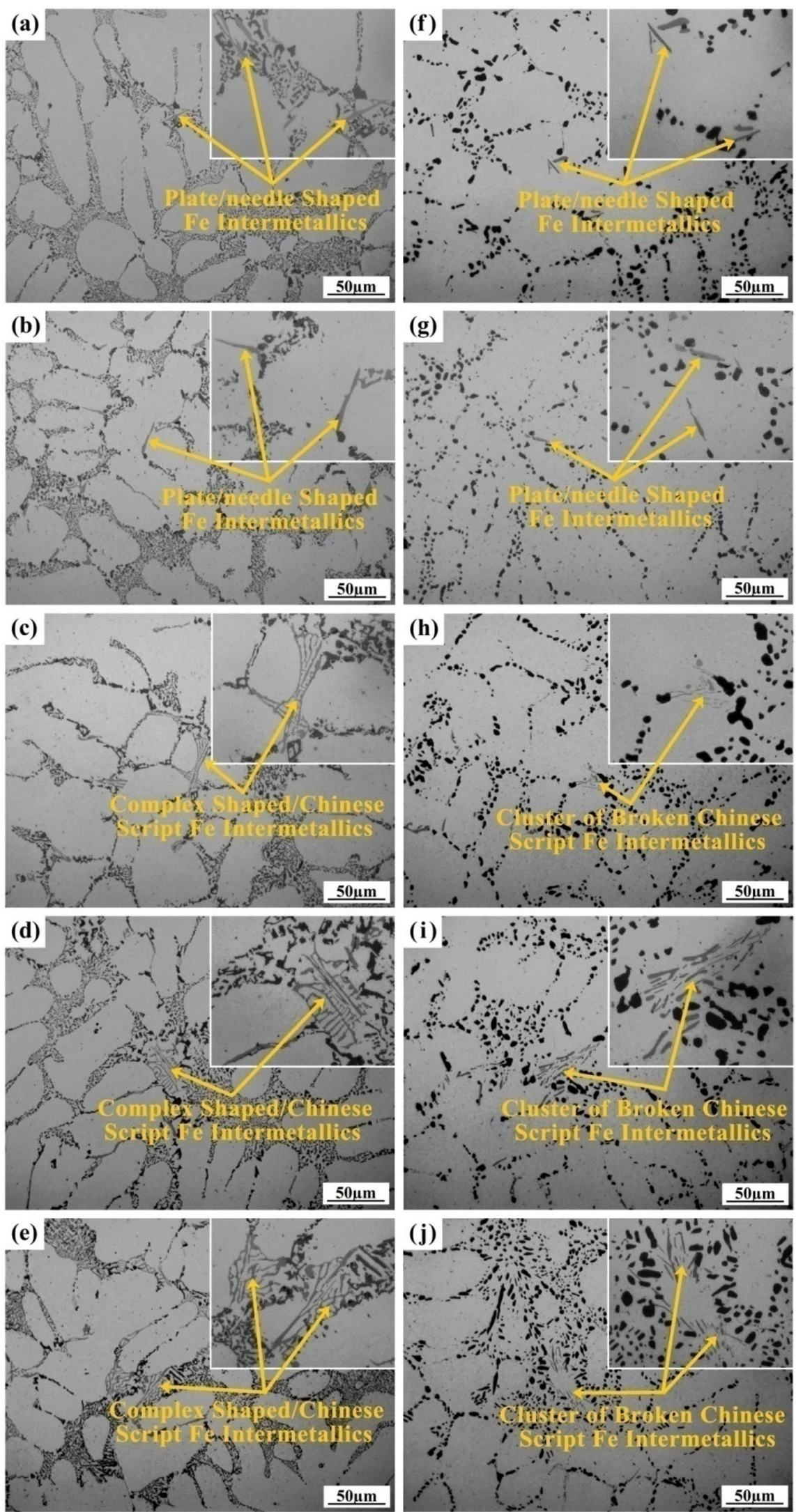
phases can be observed in Fig. 3a, f of B-0 and Fig. 3b, $g$ of B-1 alloys, which most probably could be Fe-IMCs [52]. It is quite remarkable that the morphology of these Fe-IMCs is altered from plate/needle-shape to complex/Chinesescripts whenever the $B$ is added up to 0.10 wt. \% (B-2 alloy) or higher (0.10 0.40 wt. \%) in the AC state, as shown in Fig. $3 c-$ e. However, these Chinese-scripts are broken down into accumulative clusters of plate/needle-like FeIMCs after T6 treatment, as depicted in Fig. 3h-j. Besides, it can also be noticed in the optical micrographs of Fig. 3 that the morphology of the eutectic phase (Si particles) is not same throughout the microstructures of all cast alloys. Hence the numerical (length, diameter, and aspect ratio) values of the eutectic Si particles have been computed and listed in Table 2. The measured values of the eutectic Si particles indicate that the higher B quantities $(0.20$ and $0.40 \mathrm{wt}$. \%) cause the eutectic phase to grow bigger and longer, especially the length is increased and diameter of the particles is reduced. Consequently, the higher aspect ratios can be noted for the increased $B$ amounts.

\subsection{SEM observations}

SEM-EDS mapping results of B- 0 and B-4 alloys in the AC and T6 states are displayed in Fig. 4. It can be identified that Fe-IMCs contain Mg to some extent in the AC state (Fig. 4a, c) regardless of $B$ amount; therefore, it could be reasonably inferred that these Fe-IMCs are primarily comprised of the $\pi$-Fe phase because of the existence of $\mathrm{Mg}$ $[47,51]$. However, it is quite interesting to observe that the $B$ is accumulated exactly in the same region where $\mathrm{Chi}$ nese-script is formed in Fig. 4c for B-4 alloy in the AC state. Besides, T6 treatment not only disintegrates the Chinesescript into small disoriented plate/needle-like particles as depicted in Fig. $4 \mathrm{~d}$ but also causes the simultaneous absorption of $\mathrm{Mg}$ and $\mathrm{B}$ into the solid solution of $\mathrm{a}-\mathrm{Al}$ matrix, by producing the agglomerated cluster of Fe-IMCs.

\subsection{XRD analyses and phase identification}

Figure 5 represents the X-ray Diffraction (XRD) trend lines and peaks of the various phases generated in B-0
(0.002 wt. \% of B) and B-4 (possessing 0.40 wt. \% of B) alloys both in the $A C$ and $T 6$ conditions. The $\pi-\mathrm{Al}_{8} \mathrm{Si}_{6} \mathrm{Mg}_{3}$ Fe-phase was detected in both (B-0 and B-4) alloys in the $A C$ state along with minute $\beta$-phase. Nevertheless, the $\pi$-phase peaks were entirely disappeared in both alloys after T6 treatment as can be identified in Fig. 5a-b. These results comply with the SEM-EDS analyses that heat treatment (T6) caused the complete disintegration, dissolution (of $\mathrm{Mg}$ and $\mathrm{B}$ ), and transformation of the $\pi$-Fe phase.

\subsection{Mechanical Properties}

Figure 6 exhibits the mechanical responses of the studied alloys (both in the AC and T6 states) with various B additions. In the $A C$ state, the overall mechanical properties are not changed much by increasing $B$ additions (Fig. 6a). The ductility is slightly improved (from 8.1 to $8.9 \%$ ) for higher $(0.10 \sim 0.40 \mathrm{wt}$. \%) amounts of B while the ultimate tensile strength (UTS) values of all the alloys remained almost identical except a slight increment $(6 \sim 10 \mathrm{MPa})$ in B-2 alloy. The B-0, B-1, and B-2 alloys exhibit alike values of yield strength (YS) for $0.002,0.04$, and $0.10 \mathrm{wt}$. \% additions of $B$, respectively. Whereas, a decrement (of $7 \sim 15 \mathrm{MPa}$ ) in the yield strength values can be observed for B-3 and B-4 alloys containing 0.20 and $0.40 \mathrm{wt}$. \% of $\mathrm{B}$, correspondingly. After T6 treatment, the (yield and ultimate tensile) strength characteristics of all the alloys are enhanced quite considerably as compared to the $A C$ state; whereas, the ductility trend showed marginal improvement for B-1 alloy $(0.04$ wt. \% of B) and then drastically dropped upon increasing the B quantities for B-2, B-3, and B-4 alloys (Fig. 6b). The YS and UTS values achieved by the B- 0 alloy (containing 0.002 wt. \% of B) are 302 and $349 \mathrm{MPa}$, respectively along with $5.9 \%$ of elongation. Both the ductility $(6.7 \%)$ and strength $(\mathrm{YS}=328 \mathrm{MPa}$ and UTS $=373 \mathrm{MPa}$ ) values are simultaneously reached to the maximum level for trace addition of $B$ (0.04 wt. \% for B-1 alloy). The strength and elongation values started decreasing for B-2 and B-3 alloys (possessing 0.10 and 0.20 wt. $\%$ of $B$ ); whereas, the further increment of B amount ( $0.40 \mathrm{wt}$. \% for B-4 alloy) not merely reduced the
Table 2 Quantitative characteristics of Si eutectic phase and Fe intermetallics after T6 treatment

\begin{tabular}{|c|c|c|c|c|c|}
\hline \multirow{2}{*}{$\begin{array}{l}\text { Alloy Code } \\
\text { (wt. \% of B) }\end{array}$} & \multicolumn{3}{|c|}{ Si eutectic phase } & \multicolumn{2}{|l|}{ Fe intermetallics } \\
\hline & Length $(\mu \mathrm{m})$ & Diameter $(\mu \mathrm{m})$ & Aspect Ratio & Fractional Area (\%) & Length $(\mu \mathrm{m})$ \\
\hline B-0 (0.002) & $3.44 \pm 0.45$ & $2.55 \pm 0.28$ & $1.86 \pm 0.10$ & $0.316 \pm 0.051$ & $6.98 \pm 3.54$ \\
\hline B-1 (0.04) & $3.11 \pm 0.37$ & $2.38 \pm 0.34$ & $1.74 \pm 0.15$ & $0.337 \pm 0.034$ & $6.73 \pm 3.38$ \\
\hline B-2 (0.10) & $3.35 \pm 0.41$ & $2.41 \pm 0.37$ & $1.94 \pm 0.14$ & $0.342 \pm 0.039$ & $6.86 \pm 3.21$ \\
\hline B-3 $(0.20)$ & $3.65 \pm 0.46$ & $2.54 \pm 0.32$ & $2.01 \pm 0.13$ & $0.362 \pm 0.047$ & $6.47 \pm 3.25$ \\
\hline B-4 (0.40) & $3.72 \pm 0.53$ & $2.21 \pm 0.42$ & $2.25 \pm 0.16$ & $0.353 \pm 0.054$ & $6.68 \pm 3.72$ \\
\hline
\end{tabular}



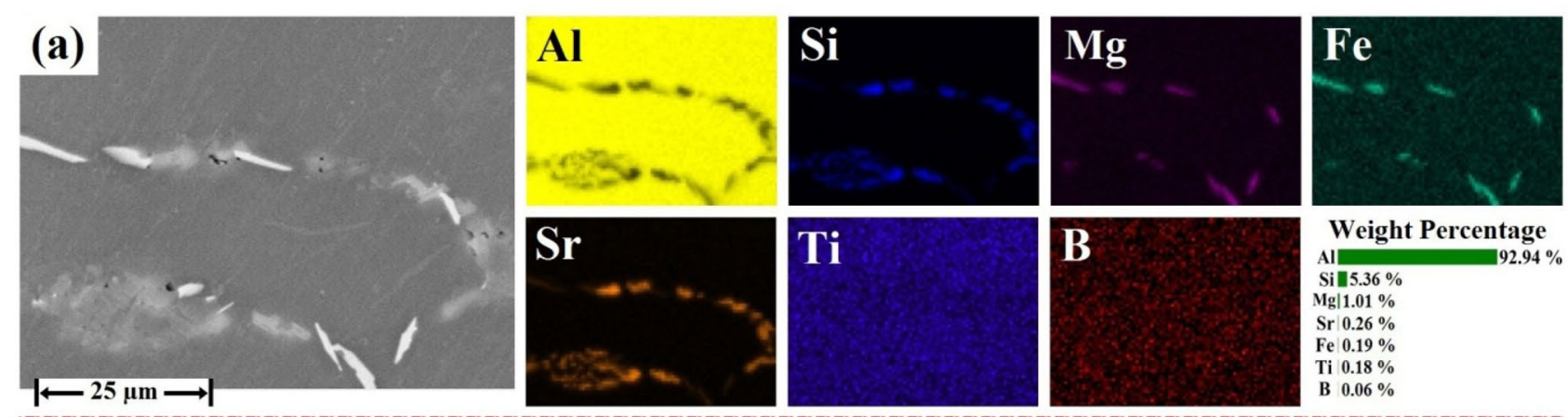

Weight Percentage Al $\quad 92.94 \%$ Sill $5.36 \%$

Sr $0.26 \%$

Fe $0.19 \%$

Ti $0.18 \%$

B $0.06 \%$
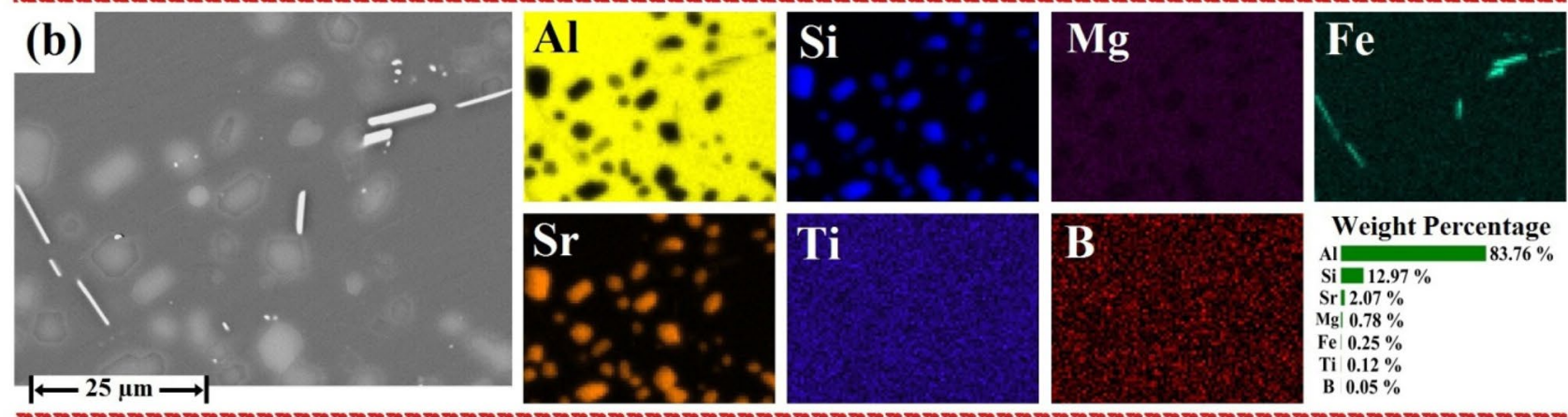

Weight Percentage Al $83.76 \%$ $\mathrm{Si}=12.97 \%$ Sr| $2.07 \%$ Mg| $0.78 \%$ Fe $0.25 \%$

Ti $0.12 \%$

B $0.05 \%$
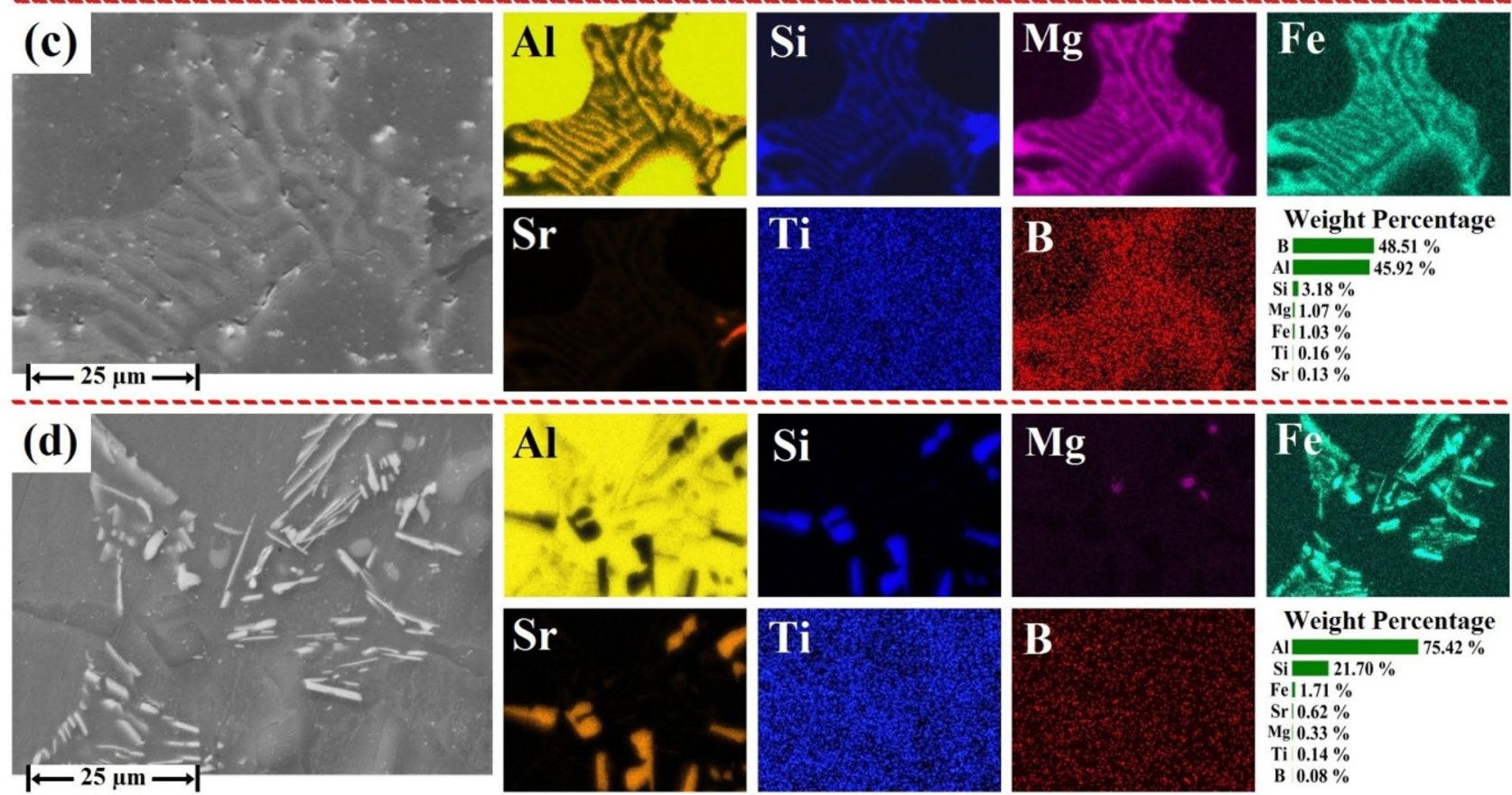

Weight Percentage

B $\quad 48.51 \%$

Al $45.92 \%$

Si $13.18 \%$

Mg| $1.07 \%$

Fel $1.03 \%$

Ti $0.16 \%$
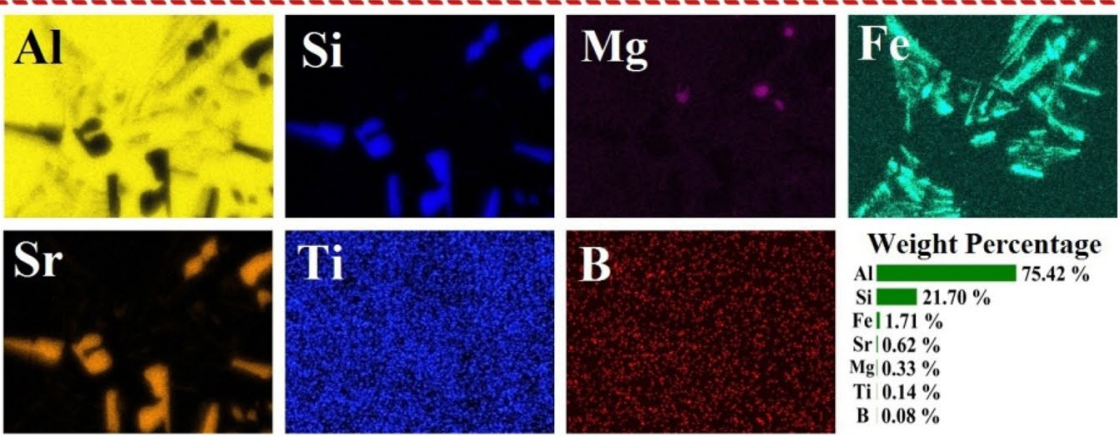

Weight Percentage Al $75.42 \%$

Fel $1.71 \%$

Fel $1.71 \%$

Srl $0.62 \%$
$\operatorname{Mg} 0.33 \%$

Ti $0.14 \%$

Ti $0.14 \%$

Fig. 4 SEM-EDS analyses of A357 cast alloys: (a-b) 0.002 and (c-d) $0.40 \mathrm{wt}$ \% of B additions with assigned names as B- 0 and B- 4 alloys, respectively; $(\mathbf{a}, \mathbf{c})$ are in the $A C$ states, while $(\mathbf{b}, \mathbf{d})$ are T6 treated samples. Note: The other alloys results are not included because

ductility from 6.7 to $1.8 \%$ but also decreased the strength properties (to YS $=297 \mathrm{MPa}$ and UTS $=327 \mathrm{MPa}$ ) as compared to the B-1 alloy.

According to the literature [60], a customized quality index (Q. I $=\mathrm{YS}_{0.2 \% \text { off }}+50 \times \%$ elongation $)$ has been of the comparable morphologies of Fe-IMCs such as B-1 is similar to B-0 (plate/needle-shape) while B-2 and B-3 are identical to B-4 (Chinese-scripts) as depicted in Fig. 3

designed to assess the overall mechanical response of the $A 356 / 357$ cast alloys, the $Q$. I values of T6 samples are measured accordingly and plotted in Fig. 6c. Additionally, the trends of the grain size, elongation, and $Q$. I values are sketched together against various $B$ additions (from 

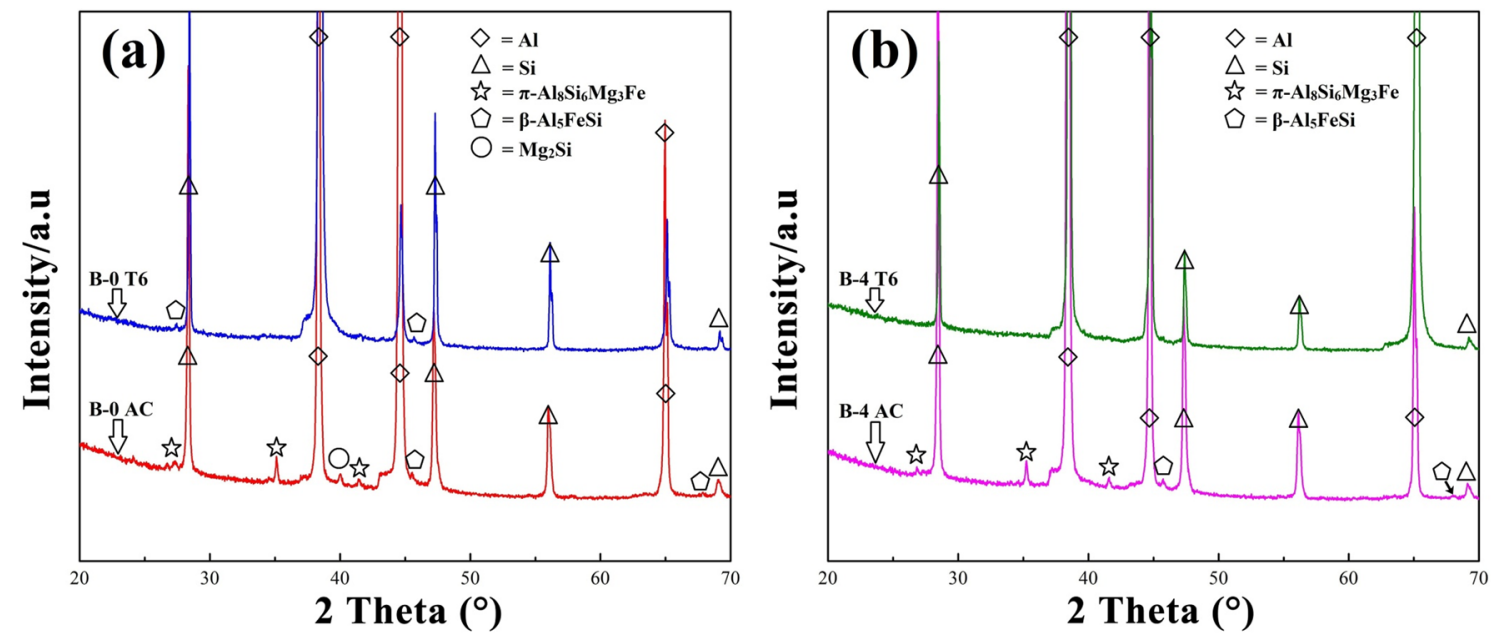

Fig. 5 XRD analyses of A357 cast alloys: (a) B-0 alloy having 0.002 wt. \% of B addition in the AC and T6 states (b) B-4 alloy containing 0.40 wt. $\%$ of $B$ in the $A C$ and $T 6$ conditions
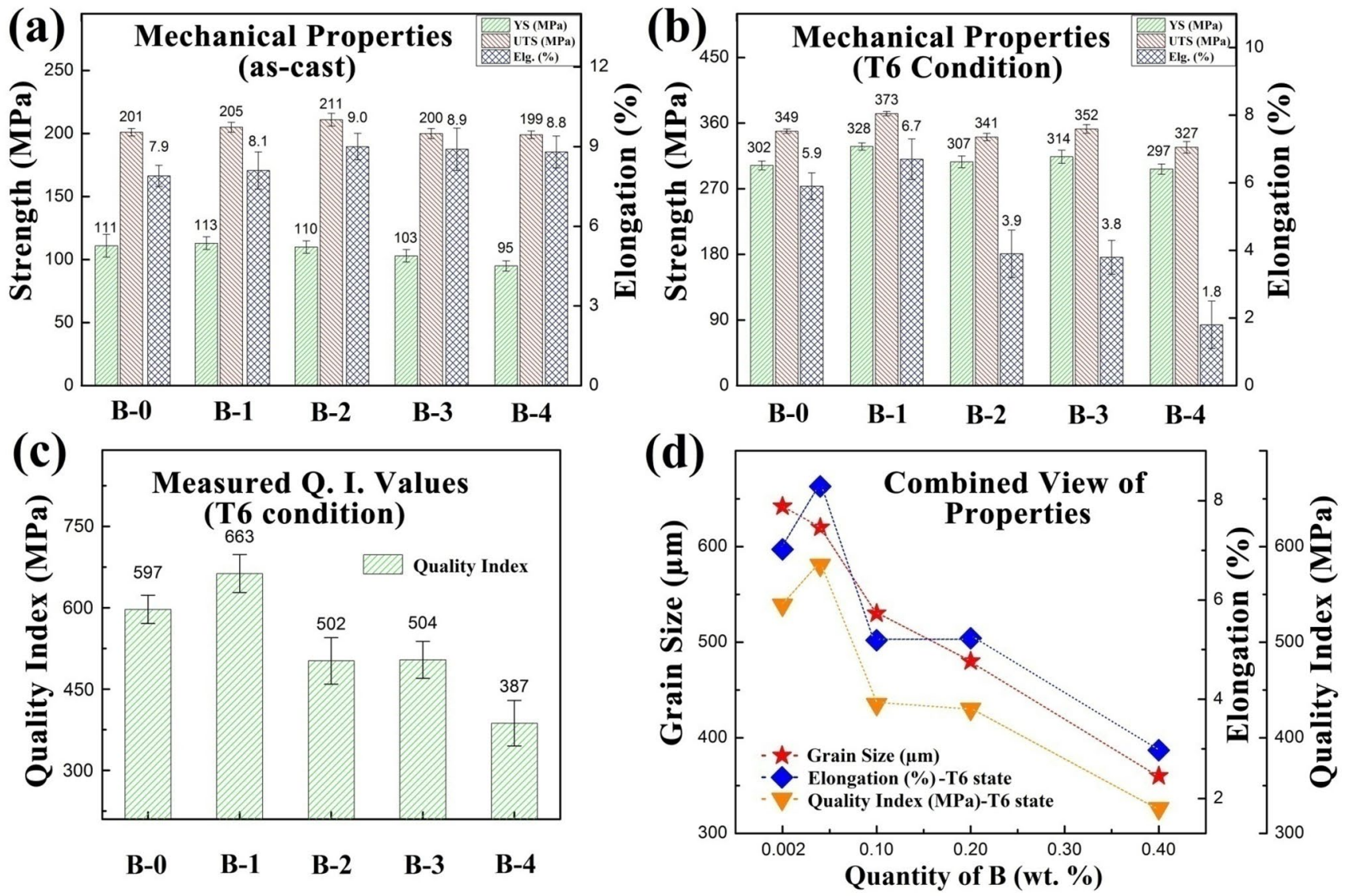

Fig. 6 Strength characteristics and graphical trends of various properties: (a-b) tensile results in the AC and T6 conditions, respectively; (c) measured values of quality index in T6 state (d) combined view of properties (grain size, elongation, and quality index plots) 
0.002 to 0.40 wt. \%) in Fig. $6 \mathrm{~d}$. It can easily be identified that all properties trend lines express identical projections and tendencies, which means they are inclined towards improving modes for the trace $B$ addition and declining trends for higher $B$ additions.

\subsection{Fracture behavior}

Figure 7 exhibits the microstructures of fractured surfaces of tensile samples. The fractured surfaces micrographs displayed in Fig. $7 a-b$ of B-1 alloy ( 0.04 wt. \% of B) indicate uniformly distributed dimples with least cleavage planes. Although, the grain size of B-1 alloy is quite larger; nevertheless, it still exhibits superior tensile properties due to the presence of the small dispersive plate/needle-type FeIMCs along with the finest eutectic Si phase characteristics (Table 2). Irrespective of the smallest grain size of B-4 alloy ( $0.40 \mathrm{wt}$. \% of B), an intergranular fracture can be observed in Fig. 7c-d representing the brittle nature of the alloy due to the presence of the agglomerated particles of Fe-IMCS near the breaking line. It gives a suitable elucidation of the lower ductility value of B-4 alloy.

\section{Discussion}

The graphical trend in Fig. $2 \mathrm{f}$ depicts that the average grain size values are dropped inversely in accordance with the added quantities of $B$. The grain size is decreased up to $360 \mu \mathrm{m}$ by supplementing the B quantity up to $0.40 \mathrm{wt}$. $\%$ (B-4 alloy), which represents $44 \%$ smaller grains as compared to B-0 alloy. Previous studies $[44,45,61]$ have also tested and verified the effectiveness of grain refinement potency of $B(A \mathrm{I}-3 \mathrm{~B})$; they reported that the absence of $\mathrm{Ti}$ and its silicides contribute significantly to the achievement of better and sustainable refinement results for extended holding times.

Two different (needle-like and Chinese-script) types of undissolved particles are observed in Fig. 3. Detailed studies suggest that the large Chinese-scripts Fe-IMCs are typically produced in A357 alloy due to the presence of an excess amount of $\mathrm{Mg}$ [50] while less $\mathrm{Mg}$ amount
Fig. 7 Microstructures of fractured tensile samples: (a-b) B-1 alloy with 0.04 wt. \% of B addition and (c-d) B-4 alloy containing 0.40 wt. \% of B; both alloys are in $\mathrm{T} 6$ conditions
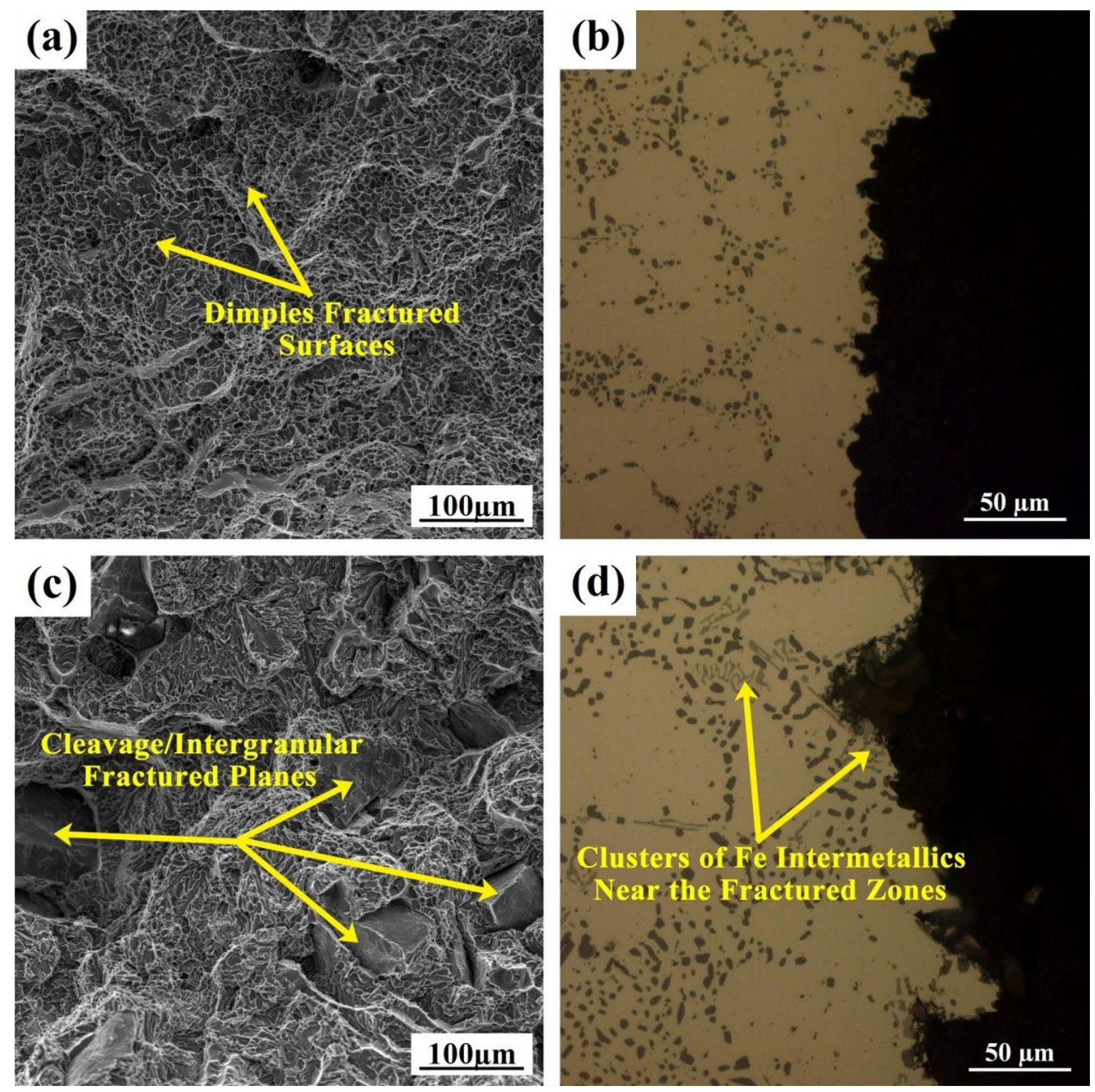

SN Applied Sciences A SPRINGer NATURE journal 
generates needle/plate-like Fe-IMCs in A356 [53]. However, only plate-like ( $\pi-\mathrm{Fe}$ ) phases are observed in B-0/B-1 alloys as exhibited in Fig. 3(a-b) in this work, although all five alloys contain similar amounts of $\mathrm{Mg}(\sim 0.50 \mathrm{wt} . \%)$ as listed in Table 1. Usually, the $\beta$ and $\pi$-Fe phases are produced as plate-like and Chinese-script morphologies, respectively during the solidification [47]. Nevertheless, Santos [62] and Caceres [52] revealed that Sr modification of A356/357 alloy poisons the $\beta$-Fe phase nucleation sites and promotes the formation of the $\pi$-Fe phase as plate-like morphologies. Therefore, it is quite logical that the $\pi-F e$ phase in B-0 and B-1 alloys appeared as plate/needle-like morphologies due to the Sr modification. However, the $\pi$-Fe phase is transformed from plate/ needle-shape to Chinese-script morphologies in B-2, B-3, and $\mathrm{B} 4$ alloys (for higher $B$ additions), even though the Sr contents are still same in these alloys.

Chen et al. [45] investigated the in depth refinement mechanism of $B$ and advocated that a momentary film of the $\mathrm{SiB}_{6}$ is generated at the interface of $\mathrm{Al}$ and $\mathrm{AlB}_{2}$, which limits the crystallographic disparity by restricting the further growth of the a-Al phase. This layer $\left(\mathrm{SiB}_{6}\right)$ is created for short period during solidification and dissolves quickly by releasing $\mathrm{Si}$ and B. As the $\pi$-Fe phase is generated through quaternary (last) reaction during solidification [49]; the released $B$ after the dissolution of the $\mathrm{SiB}_{6}$ layer slows down the eutectic reaction, which provides more settlement time for Fe particles to accumulate in the eutectic cell boundaries to form complex-shape Chinese-script morphologies.

The increased numerical (aspect ratio and length) values of the eutectic phase in Table 2 for higher $B$ additions provide a reasonable evidence of the decelerated eutectic reaction. Due to less solubility of $\mathrm{B}$ in liquidus $\mathrm{Al}$, the liberated $B$ during the refinement process is gathered around the $\pi$-Fe (possessing $\mathrm{Mg}$ ) phase due to its potential tendency to form $\mathrm{MgB}_{2}$ by reacting with $\mathrm{Mg}$ [63]; which is a fair justification of $B$ accumulation around the Chinesescript Fe-IMCs region as observed in Fig. 4c. Therefore, it can be deduced that higher B amounts $(0.10 \sim 0.40 \mathrm{wt}$. $\%)$ promoted the morphological transformation of platelike Fe-IMCs into Chinese-scripts in the AC state but after T6 treatment they had changed again into plate/needleshapes by creating regional clusters of Fe IMCs.

Wu et al. [53] reported the partial transformation of the $\pi$-phase after T6 treatment; conversely, Taylor [50] argued that that the complete transformation of the $\pi$-Fe into the $\beta$-Fe phase occurs after heat-treatment and the current study reasonably agrees with the later claim. However, XRD observations (Fig. 5b) did not show any clear additional peak/evidence of the $\beta$-phase generation after T6 treatment. Consequently, it is extremely hard to claim with surety that these $\pi$-phase Chinesescript morphologies are transformed to which phase (either $\beta$ or $\pi$-phase) after heat treatment, suggesting that this may still be unrevealed transformation demanding a further investigation in the future.

Generally, the refined grains are beneficial to the ductility improvement; however, the decrement in the ductility values is not agreeing with the monotonically declining trend of the grain size in accordance with $B$ additions. As the heat treatment causes the reduction and disintegration of the $\pi$-Fe phase (Chinese-script morphologies), hence these clustered regions of $\mathrm{Fe}$ IMCs (Fig. 3h-j and Fig. 4d) generate stress concentration (weak) areas (Fig. 7d), which lead to the premature crack initiation by deteriorating the ductility. Contrarily; despite of the relatively larger grains, the tensile properties (in particular ductility) reach their maximum values for small B (0.04 wt. \%) addition. Because B-1 alloy contains dispersive plate-like Fe-IMCs as well as the finest eutectic Si phase characteristics (Table 2). A transgranular fracture mechanism with uniformly distributed circular dimples (Fig. 7a) provides a fair reason for the enhanced ductility. The fractographic observations are fairly aligned with the microstructural observations and tensile results, which provide a rational interpretation of the ductility variations.

\section{Conclusions}

In accordance with the presented results and discussion, it may be deduced that the addition of $B$ is an extremely critical factor for A357 cast alloy and the findings can be summed up as follow;

1. Minor B ( 0.04 wt. \% through Al-3B) addition produces a comparable grain refinement effect as created by commercial grain refiner Al-5Ti-1B (by adjusting 0.002 wt. $\%$ of $B$ addition). Although, the higher amounts (0.10 0.40 wt. \%) of B appreciably decreased the grain size; meanwhile, the $\pi$-Fe phase is transformed from plate/needle-like into Chinese-script morphologies.

2. These Chinese-script morphologies are less influential on mechanical properties in the AC state; however, they are reduced and disintegrated into clusters of $\mathrm{Fe}$ particles after $\mathrm{T} 6$ treatment.

3. These agglomerated regions of Fe-IMCs act as weak points during the tensile loading and significantly damage the ductility to a considerable extent (about 73\% decrement was observed). Therefore, extreme care is required while developing $B$ containing grain refiners at an industrial scale because of the deleterious influence of higher B amounts in terms of Fe-IMCs and their consequent role in deteriorating the ductility values. 
Acknowledgements This work is funded by the National Key Research and Development Program of China (2016YFB0301000) and Shanghai Rising-Star Program (15QB1402700). The authors are also thankful to the Instrument Analysis Center of Shanghai Jiao Tong University for providing experimental and testing facilities.

Data availability The raw/processed data required to reproduce these findings are available from the corresponding author upon reasonable request.

\section{Compliance with ethical standards}

Conflict of interests The authors declare that they have no conflict of interest.

\section{References}

1. Cole GS, Sherman AM (1995) Light weight materials for automotive applications. Mater Charact 35:3-9. https://doi. org/10.1016/1044-5803(95)00063-1

2. Behera R, Chatterjee D, Sutradhar G (2012) Effect of reinforcement particles on the fluidity and solidification behavior of the stir cast aluminum alloy metal matrix composites. Am J Mater Sci 2:53-61. https://doi.org/10.5923/j.materials.20120203.04

3. Gebril MA, Omar MZ, Mohamed IF, Othman NK (2019) Microstructural evaluation and corrosion resistance of semisolid cast A356 alloy processed by equal channel angular pressing. Met 9:303. https://doi.org/10.3390/met9030303

4. Jeong CY (2013) High temperature mechanical properties of Al$\mathrm{Si}-\mathrm{Mg}-(\mathrm{Cu})$ alloys for automotive cylinder heads. Mater Trans 54:588-594. https://doi.org/10.2320/matertrans.M2012285

5. Benedyk JC (2010) Aluminum alloys for lightweight automotive structures. In: Mallick PK (ed) Materials, design and manufacturing for lightweight vehicles. Woodhead Publishing, Cambridge, pp 79-113

6. Asghar G, Peng L, Fu P, Yuan L, Liu Y (2020) Role of Mg2Si precipitates size in determining the ductility of A357 cast alloy. Mater Des. https://doi.org/10.1016/j.matdes.2019.108280

7. Lashgari H, Emamy M, Razaghian A, Najimi A (2009) The effect of strontium on the microstructure, porosity and tensile properties of A356-10\% B 4 C cast composite. Mater Sci Eng A 517:170179. https://doi.org/10.1016/j.msea.2009.03.072

8. Razaghian A, Emamy M, Najimi A, Ebrahimi SS (2009) Sr effect on the microstructure and tensile properties of $A 357$ aluminum alloy and Al 2 O 3/SiC-A357 cast composites. Mater Charact 60:1361-1369. https://doi.org/10.1016/j.matchar.2009.06.008

9. Wang T, Zheng Y, Chen Z, Zhao Y, Kang H (2014) Effects of Sr on the microstructure and mechanical properties of in situ TiB 2 reinforced A356 composite. Mater Des 64:185-193. https://doi. org/10.1016/j.matdes.2014.07.040

10. Farahany $S$, Ourdjini $A$, Idris $M$, Thai L (2011a) Effect of bismuth on microstructure of unmodified and Sr-modified Al-7Si-0.4 Mg alloys. Trans Nonf Met Soci Ch 21:1455-1464. https://doi. org/10.1016/S1003-6326(11)60881-9

11. Farahany $S$, Ourdjini A, Idris MH, Thai LT (2011b) Poisoning effect of bismuth on modification behaviour of strontium in LM25 alloy. Bull Mater Sci 34:1223-1231. https://doi.org/10.1007/ s12034-011-0239-5

12. Ahmad R, Asmael MBA (2016a) Influence of lanthanum on solidification, microstructure, and mechanical properties of eutectic Al-Si piston alloy. J Mater Eng Perfor 25:2799-2813. https://doi. org/10.1007/s11665-016-2139-8
13. Pourbahari B, Emamy M (2016) Effects of La intermetallics on the structure and tensile properties of thin section gravity die-cast A357 Al alloy. Mater Des 94:111-120. https://doi.org/10.1016/j. matdes.2016.01.039

14. Yu B-B, Yan H, Zhu J-B, Liu J-L, Li H-G, Nie Q (2019) Effects of La on microstructure and corrosion behavior of AISi5Cu1Mg Alloy. Acta Metall Sin (Eng Lett) 32:443-451. https://doi.org/10.1007/ s40195-018-0782-9

15. Tsai Y-C, Chou C-Y, Lee S-L, Lin C-K, Lin J-C, Lim S (2009) Effect of trace $L a$ addition on the microstructures and mechanical properties of $\mathrm{A} 356$ (Al-7Si-0.35Mg) aluminum alloys. J Alloy Compd 487:157-162. https://doi.org/10.1016/j.jallcom.2009.07.183

16. Ahmad R, Asmael MBA (2016b) Influence of cerium on microstructure and solidification of eutectic Al-Si piston alloy. Mater Manuf Process 31:1948-1957. https://doi.org/10.1080/10426 914.2015.1127942

17. Jiang W, Fan Z, Dai Y, Li C (2014) Effects of rare earth elements addition on microstructures, tensile properties and fractography of A357 alloy. Mater Sci Eng A 597:237-244. https://doi. org/10.1016/j.msea.2014.01.009

18. Pramod S, Rao AP, Murty B, Bakshi SR (2015) Effect of Sc addition on the microstructure and wear properties of A356 alloy and A356-TiB 2 in situ composite. Mater Des 78:85-94. https://doi. org/10.1016/j.matdes.2015.04.026

19. Xu C, Jiang Q, Yang $Y$, Wang $H$, Wang J (2006) Effect of Nd on primary silicon and eutectic silicon in hypereutectic $\mathrm{Al}-\mathrm{Si}$ alloy. J Alloy Compd 422:L1-L4. https://doi.org/10.1016/j.jallc om.2005.03.128

20. Li B, Wang H, Jie J, Wei Z (2011) Effects of yttrium and heat treatment on the microstructure and tensile properties of Al-7.5 Si-0.5 Mg alloy. Mater Des 32:1617-1622. https://doi. org/10.1016/j.matdes.2010.08.040

21. Wei Z, Lei Y, Yan H, Xu X, He J (2019) Microstructure and mechanical properties of $A 356$ alloy with yttrium addition processed by hot extrusion. J Rare Earths 37:659-667. https://doi. org/10.1016/j.jre.2018.11.008

22. McCartney D (1989) Grain refining of aluminium and its alloys using inoculants. Int Mater Rev 34:247-260. https://doi. org/10.1179/imr.1989.34.1.247

23. Easton MA, Wang H, Grandfield J, Davidson CJ, StJohn DH, Sweet LD, Couper MJ (2012) Observation and prediction of the hot tear susceptibility of ternary Al-Si-Mg alloys. Metall Mater Trans A 43:3227-3238. https://doi.org/10.1007/s11661-012-1132-6

24. Lee C (2016) Effect of Ti-B addition on the variation of microporosity and tensile properties of A356 aluminium alloys. Mater Sci Eng A 668:152-159. https://doi.org/10.1016/j.msea.2016.05.059

25. Murty BS, Kori SA, Chakraborty M (2002) Grain refinement of aluminium and its alloys by heterogeneous nucleation and alloying. Int Mater Rev 47:3-29. https://doi.org/10.1179/09506 6001225001049

26. Arnberg L, Bäckerud L, Klang H (1982) Intermetallic particles in $\mathrm{Al}-\mathrm{Ti}-\mathrm{B}$-type master alloys for grain refinement of aluminium. Met Tech 9:7-13. https://doi.org/10.1179/030716982803286368

27. Guzowski MM, Sigworth GK, Sentner DA (1987) The role of boron in the grain refinement of aluminum with titanium. Metall Trans A 18A:603-620. https://doi.org/10.1007/BF02649476

28. O'Reilly K, Cantor B, Enright P (1993) Nucleation of solidification in Al-transition metal alloys. Scripta Metall et Mater 28:173-177. https://doi.org/10.1016/0956-716X(93)90558-A

29. Fan Z, Wang Y, Zhang Y, Qin T, Zhou XR, Thompson GE, Pennycook T, Hashimoto $T$ (2015) Grain refining mechanism in the Al/Al-Ti-B system. Acta Mater 84:292-304. https://doi. org/10.1016/j.actamat.2014.10.055

30. Zhang Z, Bian X, Wang Y, Liu X (2003) Microstructure and grain refining performance of melt-spun $\mathrm{Al}-5 \mathrm{Ti}-1 \mathrm{~B}$ master alloy. 
Mater Sci Eng A 352:8-15. https://doi.org/10.1016/S0921 -5093(02)00070-9

31. Zhao ZY, Guan RG, Guan XH, Zhang J, Sun XP, Liu HN (2015) Effects of electromagnetic stirring, shearing, and extrusion on TiB2 and TiAl3 particles in Al-5Ti-1B(wt.\%) alloy. Mater Manuf Process 30:1223-1228. https://doi.org/10.1080/10426 914.2015.1019109

32. Qiu D, Taylor J, Zhang M, Kelly P (2007) A mechanism for the poisoning effect of silicon on the grain refinement of $\mathrm{Al}-\mathrm{Si}$ alloys. Acta Mater 55:1447-1456. https://doi.org/10.1016/j.actam at.2006.09.046

33. Dong $X$, Ji S (2018) Si poisoning and promotion on the microstructure and mechanical properties of $\mathrm{Al}-\mathrm{Si}-\mathrm{Mg}$ cast alloys. J Mater Sci 53:7778-7792. https://doi.org/10.1007/s1085 3-018-2022-0

34. Li Y, Hu B, Liu B, Nie A, Gu Q, Wang J, Li Q (2020) Insight into Si poisoning on grain refinement of Al-Si/Al-5Ti-B system. Acta Mater 187:51-65. https://doi.org/10.1016/j.actamat.2020.01.039

35. Kori S, Murty B, Chakraborty M (2000a) Development of an efficient grain refiner for Al-7Si alloy. Mater Sci Eng A 280:58-61. https://doi.org/10.1016/S0921-5093(99)00656-5

36. Nie J, Ma X, Ding H, Liu X (2009) Microstructure and grain refining performance of a new Al-Ti-C-B master alloy. J Alloy Compd 486:185-190. https://doi.org/10.1016/j.jallcom.2009.06.190

37. Nie J, Ma X, Li P, Liu X (2011) Effect of B/C ratio on the microstructure and grain refining efficiency of $\mathrm{Al}-\mathrm{Ti}-\mathrm{C}-\mathrm{B}$ master alloy. J Alloy Compd 509:1119-1123. https://doi.org/10.1016/j.jallc om.2010.09.180

38. Li P, Liu S, Zhang L, Liu X (2013) Grain refinement of A356 alloy by Al-Ti-B-C master alloy and its effect on mechanical properties. Mater Des 47:522-528. https://doi.org/10.1016/j.matde s.2012.12.033

39. Li Y, Hu B, Gu Q, Liu B, Li Q (2019) Achievement in grain-refining hypoeutectic Al-Si alloys with Nb. Scr Mater 160:75-80. https:// doi.org/10.1016/j.scriptamat.2018.09.037

40. Nowak M, Bolzoni L, Hari Babu N (2015) Grain refinement of $\mathrm{Al}-\mathrm{Si}$ alloys by $\mathrm{Nb}-\mathrm{B}$ inoculation. Part I: concept development and effect on binary alloys. Mater Des 66:366-375. https://doi. org/10.1016/j.matdes.2014.08.066

41. Bolzoni L, Babu NH (2015) Refinement of the grain size of the LM25 alloy (A356) by $96 \mathrm{Al}-2 \mathrm{Nb}-2 \mathrm{~B}$ master alloy. J Mater Process Tech 222:219-223. https://doi.org/10.1016/j.jmatprotec 2015.03.011

42. Xu J, Li Y, Hu B, Jiang Y, Li Q (2019) Development of Al-Nb-B master alloy with high $\mathrm{Nb} / \mathrm{B}$ ratio for grain refinement of hypoeutectic Al-Si cast alloys. J Mater Sci 54:14561-14576. https ://doi.org/10.1007/s10853-019-03915-9

43. Bolzoni L, Nowak M, Hari Babu N (2015) Grain refinement of AlSi alloys by Nb-B inoculation. Part II: application to commercial alloys. Mater Des 66:376-383. https://doi.org/10.1016/j.matde s.2014.08.067

44. Birol Y (2012) Performance of AITi5B1, AITi3B3 and AIB3 master alloys in refining grain structure of aluminium foundry alloys. Mater Sci Tech 28:481-486. https://doi.org/10.1179/1743284711 Y.0000000058

45. Chen Z, Kang H, Fan G, Li J, Lu Y, Jie J, Zhang Y, Li T, Jian X, Wang T (2016) Grain refinement of hypoeutectic Al-Si alloys with B. Acta Mater 120:168-178. https://doi.org/10.1016/j.actam at.2016.08.045

46. Birol Y (2014) Grain refining aluminium foundry alloys with commercial Al-B master alloys. Mater sci tech 30:277-282. https:// doi.org/10.1179/1743284713Y.0000000350

47. Mbuya TO, Odera BO, Ng'ang'a SP (2003) Influence of iron on castability and properties of aluminium silicon alloys: literature review. Int J Cast Metal Res 16:451-465. https://doi. org/10.1080/13640461.2003.11819622
48. Wang $Q$, Jones P, Osborne M (2003) Effect of iron on the microstructure and mechanical properties of an $\mathrm{Al}-7 \% \mathrm{Si}-0.4 \% \mathrm{Mg}$ casting alloy. SAE Int J Mater Manuf 112:396-404. https://doi. org/10.4271/2003-01-0823

49. Elsharkawi E, Samuel E, Samuel A, Samuel F (2010) Effects of $\mathrm{Mg}, \mathrm{Fe}, \mathrm{Be}$ additions and solution heat treatment on the $\pi$-AlMgFeSi iron intermetallic phase in $\mathrm{Al}-7 \mathrm{Si}-\mathrm{Mg}$ alloys. J Mater Sci 45:1528-1539. https://doi.org/10.1007/s10853-009-4118-z

50. Taylor JA (2012) Iron-containing intermetallic phases in Al-Si based casting alloys. Proc Mater Sci 1:19-33. https://doi. org/10.1016/j.mspro.2012.06.004

51. Yıldırım M, Özyürek D (2013) The effects of Mg amount on the microstructure and mechanical properties of $\mathrm{Al}-\mathrm{Si}-\mathrm{Mg}$ alloys. Mater Des 51:767-774. https://doi.org/10.1016/j.matde s.2013.04.089

52. Caceres C, Davidson C, Griffiths J, Wang Q (1999) The effect of $\mathrm{Mg}$ on the microstructure and mechanical behavior of Al-Si-Mg casting alloys. Metall Mater Trans A 30:2611-2618. https://doi. org/10.1007/s11661-999-0301-8

53. Wu X, Zhang H, Ma Z, Tao T, Gui J, Song W, Yang B, Zhang H (2019) Interactions between Fe-rich intermetallics and Mg-Si phase in Al-7Si-xMg alloys. J Alloy Compd 786:205-214. https ://doi.org/10.1016/j.jallcom.2019.01.352

54. Yang C-Y, Lee S-L, Lee C-K, Lin J-C (2005) Effects of Be and Fe on the mechanical and corrosion behaviors of $A 357$ alloys. Mater Chem Phys 93:412-419. https://doi.org/10.1016/j.matchemphy s.2005.03.029

55. Kim HY, Park TY, Han SW, Lee HM (2006) Effects of Mn on the crystal structure of a-Al(Mn, Fe)Si particles in A356 alloys. J Crys Gro 291:207-211. https://doi.org/10.1016/j.jcrysgro.2006.02.006

56. Tzeng YC, Wu CT, Bor HY, Horng JL, Tsai ML, Lee SL (2014) Effects of scandium addition on iron-bearing phases and tensile properties of Al-7Si-0.6 Mg alloys. Mater Sci Eng A 593:103-110. https://doi.org/10.1016/j.msea.2013.11.039

57. Kim HY, Han SW, Lee HM (2006) The influence of Mn and $\mathrm{Cr}$ on the tensile properties of A356-0.20 Fe alloy. Mater Lett 60:18801883. https://doi.org/10.1016/j.matlet.2005.12.042

58. Shi Z, Wang Q, Zhao G, Zhang R (2015) Effects of erbium modification on the microstructure and mechanical properties of A356 aluminum alloys. Mater Sci Eng A 626:102-107. https:// doi.org/10.1016/j.msea.2014.12.062

59. Colombo M, Gariboldi E, Morri A (2017) Er addition to Al-Si-Mgbased casting alloy: effects on microstructure, room and high temperature mechanical properties. J Alloy Compd 708:12341244. https://doi.org/10.1016/j.jallcom.2017.03.076

60. Din T, Rashid A, Campbell J (1996) High strength aerospace casting alloys: quality factor assessment. Mater Sci Tech 12:269-273. https://doi.org/10.1179/mst.1996.12.3.269

61. Kori S, Murty B, Chakraborty M (2000b) Development of an efficient grain refiner for $\mathrm{Al}-7 \mathrm{Si}$ alloy and its modification with strontium. Mater Sci Eng A 283:94-104. https://doi.org/10.1016/ S0921-5093(99)00794-7

62. Santos J, Jarfors AEW, Dahle AK (2019) Formation of iron-rich intermetallic phases in Al-7Si-Mg: influence of cooling rate and strontium modification. Metall Mater Trans A 50:4148-4165. https://doi.org/10.1007/s11661-019-05343-5

63. Cooley L, Kang K, Klie R, Li Q, Moodenbaugh A, Sabatini R (2004) Formation of MgB2 at low temperatures by reaction of Mg with B6Si. Supercond Sci Tech 17:942. https://doi. org/10.1088/0953-2048/17/7/020

Publisher's Note Springer Nature remains neutral with regard to jurisdictional claims in published maps and institutional affiliations. 